\title{
Optimal Operation of Green Campus based on Demand Response
}

\author{
Jun-Young Kim, Ji-Hye Lee, and Hak-Man Kim* \\ Incheon National University \\ hmkim@incheon.ac.kr
}

\begin{abstract}
Recently, the smart grid and microgrid based on information technology (IT) and their applications have being studied worldwide because of its high-efficiency energy consumption and variety of energy. Many universities are studying a green campus to operate the energy system efficiently based on the microgrid. Especially, it is important to meet the balance between energy supply and load with minimal cost in the green campus operation. Especially, the demand response $(D R)$ is an important function of optimal operation on the smart grid environment. In this paper, a mathematical model for optimal operation based on DR of the energy system of the green campus is proposed. Through the simulation, its feasibility is tested and analyzed.
\end{abstract}

Keywords: Green campus, microgrid, optimal operation, demand response.

\section{Introduction}

Recently, the concept of smart grid and microgrid based on information technology (IT) has been developing constantly [1-6]. In addition, the energy systems of university campuses have been studying to improve effective energy use of university campuses and they are very similar to the microgrid concept as an energy community. The green campus systems are focused on effective energy use and reduction of green-house gases. For these reasons, effective energy use and reduction of green-house gases are considered in operation of energy systems of green campuses as key technologies [5-11].

Meanwhile, demand response (DR) which can change the load patterns of customers by the real-time electricity prices has been studying as a flexible energy resource in microgrid operation [14-17]. Reference [14] dealt with three types of loads according to load characteristics for applying the DR function to operation. In reference [15], a customer reward (CR) scheme was proposed for shiftable and adjustable loads and an index considering priority and flexibility of customers was modeled to compute reduction amounts by load ranking. In reference [16], a day-ahead algorithm for DR was proposed based on load forecasting. In reference [17], an operation scheduling was proposed based on base load, schedulable load, plug-in electric vehicle load, and distributed generation as negative loads to maximize fluctuation costs by DR. In addition, it is anticipated that the incentive program for DR will be introduced in the energy systems of the green campuses in the near future.

This paper deals with an optimal operation for the green campus. For applying DR to the optimal operation of the green campus, the electrical load is classified in three parts: the fixed load, the shiftable load, and the adjustable load. A mathematical model is proposed to optimally operate the energy systems of the green campus considering the load characteristics. Through the simulation, its feasibility is tested and analyzed.

${ }^{*}$ Corresponding Author 


\section{Configuration of energy system of green campus}

Energy systems of green campuses are composed of various types according to geographical campus environments. However, the green campus includes energy sources, energy storage systems, and loads generally. Energy source can be classified in two types: controllable distributed generators, such as a diesel generator and a combined heat and power generator (CHP) generator, and uncontrollable generators, such as renewable energy sources as shown in Figure 1, where DG means a diesel generator. Loads are composed of electricity and thermal loads basically. As mentioned before, the electricity loads can be classified with three types according to the following load characteristics; firstly fixed load, which can't be interrupted and shifted during the operation intervals, secondly the shiftable load, which can be moved to other intervals without affecting and often can involve a non-interruptible process, and finally the adjustable load, which can't be shifted to other intervals without affecting and can be interrupted instantly [15-16]. In addition, it is assumed that an incentive for DR is applied to the adjustable load. In the case of thermal energy, it is assumed that there is no interaction with a thermal energy grid on the outside of the university campus. As a result, the CHP generators and the heat only boilers (HOBs) should supply required thermal energy of the campus.

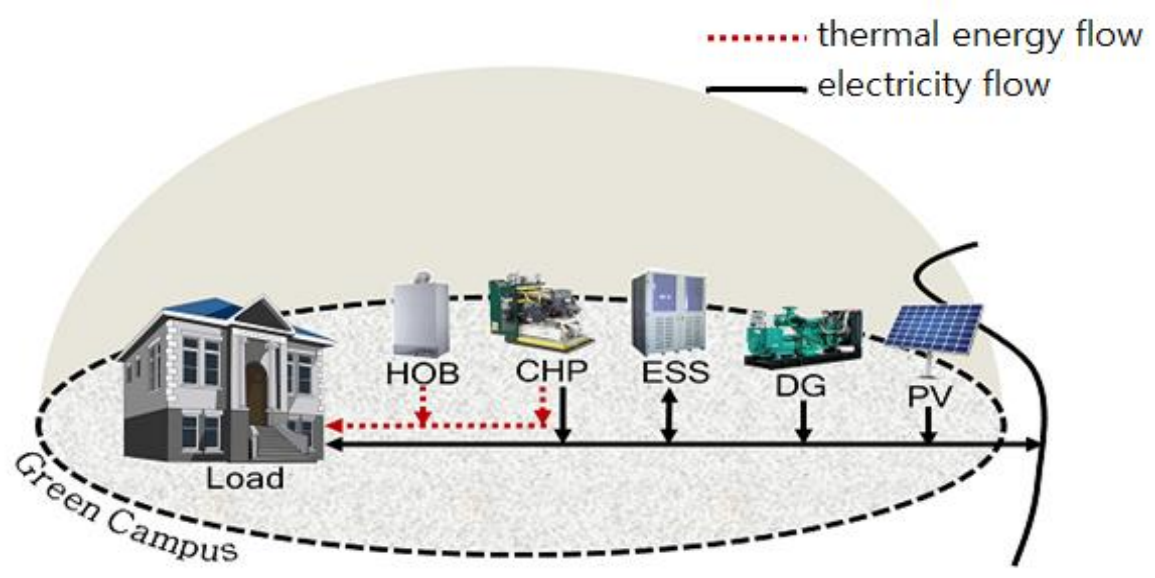

Figure 1. An example of configuration of energy system of green campus

\section{Mathematical model for optimal operation}

The objective function is established to minimize the costs of green campus operation as shown in equation (1), where the first term means the production cost of controllable distribute generators (CDGs), the second term means the production cost of combined heat and power generators (CHPs), the third term means the heat production cost of heat only boilers (HOBs), the fourth term means the cost of buying electricity from the power market, the fifth term means income by selling electricity to the power market, and the final term means the incentive for adjustable loads. The incentive for adjustable load depends on the amount of reduction load in the specific adjustable interval.

$$
\begin{aligned}
& \operatorname{Min} \mathrm{C}=\sum_{t=1}^{T}\left\{\sum_{i=1}^{I}\left(C_{i, D G} \cdot P_{i, D G}(t)\right)+\sum_{j=1}^{J}\left(C_{j, C H P} \cdot P_{j, C H P}(t)\right)+\sum_{k=1}^{K}\left(C_{k, H O B} \cdot H_{k, H O B}(t)\right)\right\} \\
& +\sum_{t=1}^{T}\left\{P R_{B U Y}(t) \cdot P_{B U Y}(t)-P R_{S E L L}(t) \cdot P_{S E L L}-P R_{I N C E N}(t) \cdot P_{L O A D}^{A}(t) \cdot u(t)\right\} \\
& \text { where } \\
& \text { for } 1 \leq t \leq T
\end{aligned}
$$




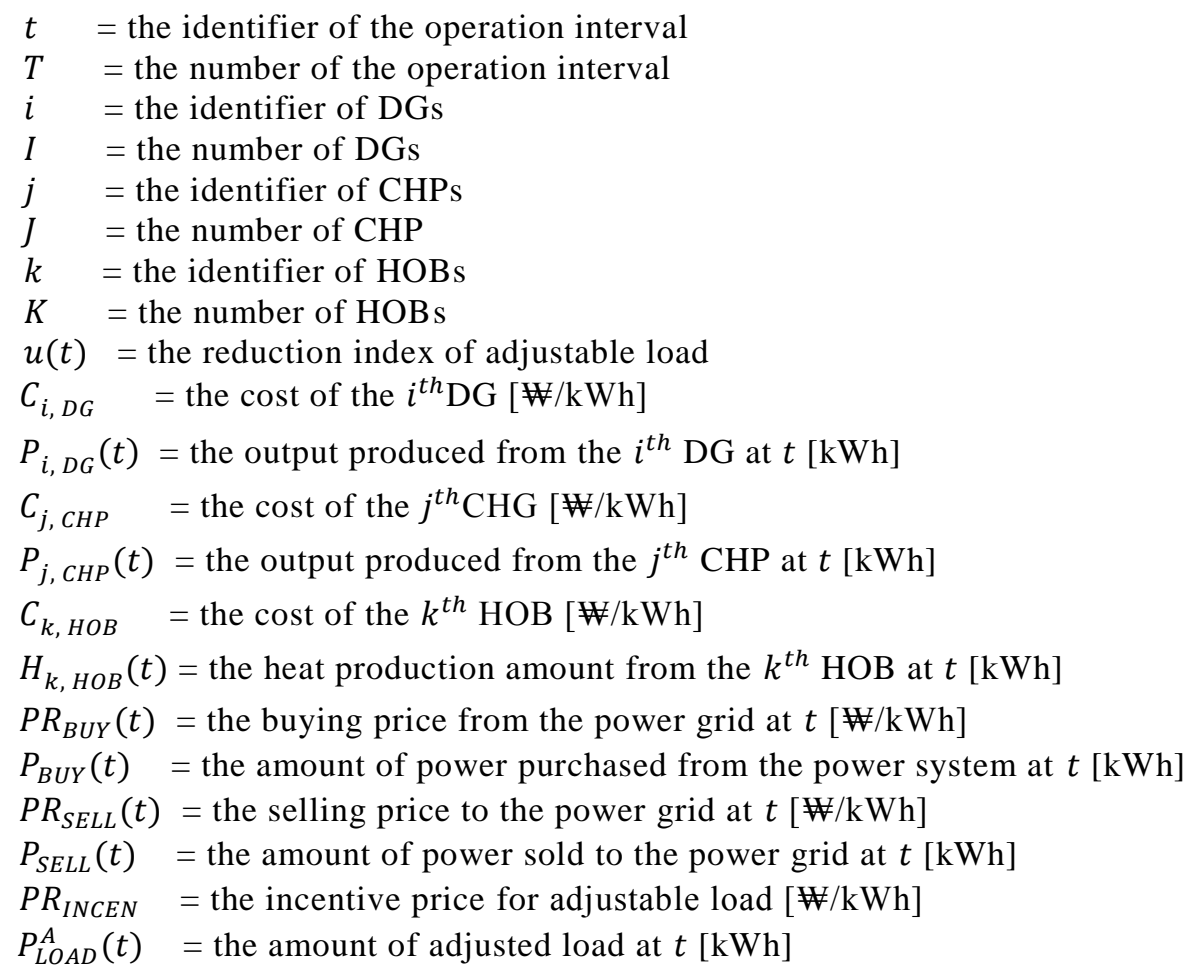

Operation constraints for energy facilities in the green campus are defined as equations (2) - (11). The production capacities of the facilities are defined as follow. Equation (2) shows the generation capacities of DGs. Similarly, equations (3) and (4) show the generation capacities of CHPs and HOBs.

The generation capacity of DG: $\min \left[P_{i, D G}\right] \leq P_{i, D G}(t) \leq \max \left[P_{i, D G}\right]$

The generation capacity of CHP: $\min \left[P_{j, C H P}\right] \leq P_{j, C H P}(t) \leq \max \left[P_{j, C H P}\right]$

The generation capacity of $\mathrm{HOB}: \min \left[H_{k, \mathrm{HOB}}\right] \leq H_{k, \mathrm{HOB}}(t) \leq \max \left[H_{k, \mathrm{HOB}}\right]$

Equation (5) shows the balance constraint between thermal energy supply and demand. In this paper, thermal energy network of green campus is considered to be not connected to other systems outside.

$$
\begin{aligned}
& H_{L O A D}(t) \leq \sum_{j=1}^{J} H_{j, C H P}(t)+\sum_{k=1}^{K} H_{k, H O B}(t) \\
& \text { where } \\
& \qquad \begin{array}{l}
H_{L O A D}(t)=\text { heat demand }[\mathrm{kWh}] \\
H_{j, C H P}(t)=\text { the heat production amount of the } j^{t h} \mathrm{CHP} \text { at } t[\mathrm{kWh}]
\end{array}
\end{aligned}
$$

Equations (6) and (7) show the heat and electric power ratio of CHPs. The ratio can be variable within minimum and maximum limits.

The heat and electric power ratio of CHP: $\max \left[\eta_{j, C H P}\right] \leq \eta_{j, C H P}(t) \leq \max \left[\eta_{j, C H P}\right]$

The heat and electric power ratio: $H_{j, C H P}(t)=\eta_{j, C H P} \cdot P_{j, C H P}(t)$,

where

$$
\eta_{j, C H P}(t)=\text { the heat and electric power ratio of the } j^{t h} \text { CHP [\%] }
$$


Equation (8) shows the state of charge (SOC) and the initial value in the energy storage system (ESS).

$$
\begin{aligned}
& P_{m, E S S} \cdot E_{m, S O C}(t)=P_{m, E S S} \cdot E_{m, S O C}(t-1)+P_{m, E S S}^{c h}(t)-P_{m, E S S}^{d c h}(t) \\
& \text { if } t=1 \text {, then } P_{m, E S S} \cdot E_{m, S O C}(t-1)=P_{m, E S S}^{\text {int }} \\
& \text { where } \\
& \quad m=\text { the identifier of ESS } \\
& \quad P_{m, E S S}=\text { the maximum electricity capacity of } m^{\text {th }} \text { ESS }[\mathrm{kWh}] \\
& P_{m, E S S}^{\text {int }}=\text { the initial electricity capacity of } m^{t h} \mathrm{ESS}[\mathrm{kWh}] \\
& \quad E_{m, S O C}(t)=\mathrm{SOC} \text { of } m^{\text {th }} \mathrm{ESS} \text { at } t[\%]
\end{aligned}
$$

The amounts of charging and discharging are limited considering SOC of ESS. Thus, equation (9) shows the charging capacity of ESS and equation (10) shows the discharging capacity of ESS.

Charging amount of ESS:

$$
\begin{gathered}
0 \leq \eta_{m, E S S} \cdot P_{m, E S S}^{c h}(t) \leq P_{m, E S S} \cdot \max \left[E_{m, S O C}\right]-P_{m, E S S} \cdot E_{m, S O C}(t-1) \\
\text { if } t=1, \text { then } P_{m, E S S} \cdot E_{m, S O C}(t-1)=P_{m, E S S}^{\text {imt }}
\end{gathered}
$$

Discharging amount of ESS:

$$
\begin{aligned}
& 0 \leq 1 / \eta_{m, E S S} \cdot P_{m, E S S}^{d c h}(t) \leq P_{m, E S S} \cdot E_{m, S O C}(t-1) \\
& \quad \text { if } t=1 \text {, then } P_{m, E S S} \cdot E_{m, S O C}(t-1)=P_{m, E S S}^{i n t},
\end{aligned}
$$

where

$$
\begin{aligned}
& P_{m, E S S}^{d c h}(t)=\text { the amount of discharging power from the } m^{\text {th }} \text { ESS at } t[\mathrm{kWh}] \\
& P_{m, E S S}^{c h}(t)=\text { the amount of charging power from the } m^{\text {th }} \text { ESS at } t[\mathrm{kWh}] \\
& \eta_{m, E S S}(t)=\text { the charging and discharging ratio of } m^{t h} \text { ESS [\%] }
\end{aligned}
$$

Equation (11) shows the SOC capacity of ESS. This capacity means ESS should be operated within the allowed range. It depends on characteristic of ESS.

$$
\min \left[E_{m, S O C}\right] \leq E_{m, S O C}(t) \leq \max \left[E_{m, S O C}\right]
$$

Equations (12) - (18) show the constraints for the electricity demand, the adjustable load and the shiftable load. Equation (12) means the balance constraint between supply and demand in the electricity.

$$
\begin{aligned}
& P_{L O A D}^{F}(t)+P_{L O A D}^{S^{\prime}}(t)+P_{L O A D}^{A^{\prime}}(t)=\sum_{i=1}^{I} P_{i, D G}(t)+\sum_{j=1}^{J} P_{j, C H P}(t)+\sum_{l=1}^{L} P_{l, P V}(t) \\
& +P_{B U Y}(t)-P_{S E L L}(t)+P_{m, E S S}^{d c h}(t)-P_{m, E S S}^{c h}(t)
\end{aligned}
$$

where

$$
\begin{aligned}
& l=\text { the identifier of photovoltaic power generator }(\mathrm{PV}) \\
& L=\text { the number of PV } \\
& P_{L O A D}^{S^{\prime}}(t)=\text { the shiftable load demand at } t[\mathrm{kWh}] \\
& P_{L O A D}^{F}(t)=\text { the fixed load demand at } t[\mathrm{kWh}] \\
& P_{L O A D}^{A^{\prime}}(t)=\text { the adjustable load demand at } t[\mathrm{kWh}] \\
& P_{l, P V}(t)=\text { the output of } l^{\text {th }} \mathrm{PV} \text { at } t[\mathrm{kWh}]
\end{aligned}
$$


The adjustable load can be reduced based on real-time trading price by customers. There are more adjustable loads in some intervals having high load amounts. Thus, loads in some intervals required low energy amounts are considered as the criteria of reduction loads. On the other hand, optimal scheduling of the energy system of the green campus can decide the reduction plans in intervals having larger demand amounts than the criteria. In addition, the start point of unadjustable intervals is $a$ and the ending point of unadjustable intervals is $b$. Equation (13) shows calculation of the reference load for the reduction of adjustable loads.

$$
\begin{aligned}
& P_{L O A D}^{\text {total }}(t)=\sum_{t=a}^{b}\left(P_{L O A D}^{F}(t)+P_{L O A D}^{S}(t)+P_{L O A D}^{\text {input }}(t)\right) \\
& P_{L O A D}^{a \text { avr }}=\frac{P_{L O A D}^{\text {total }}}{(b-a+1)} \text {, for } a \leq t \leq b, \\
& \text { where } \\
& \qquad P_{L O A D}^{\text {total }}=\text { total electricity load demand in unadjusted interval }[\mathrm{kWh}] \\
& \quad P_{L O A D}^{\text {avr }}=\text { average load demand in unadjusted interval }[\mathrm{kWh}]
\end{aligned}
$$

Adjustable loads can be reduced in the intervals having adjustable loads more than $k$ times of the reference load.

$$
u(t)=\left\{\begin{array}{ll}
1, & \text { when } P_{L O A D}^{A}(t) \geq k \cdot P_{L O A D}^{a v r} \\
0, & \text { when } P_{L O A D}^{A}(t)<k \cdot P_{L O A D}^{a v r}
\end{array},\right.
$$

where

$$
\begin{aligned}
& k=\text { the reduction ratio of adjustable load interval compared with the average load } \\
& \text { for the unadjustable load interval }[\%]
\end{aligned}
$$

Equation (15) shows the relation between the adjustable load and the nonadjustable load.

$$
P_{L O A D}^{A^{\prime}}(t)+P_{L O A D}^{A}(t)=P_{L O A D}^{\text {input }}(t)
$$

The adjustable load can be reduced by equation (16).

$$
\begin{aligned}
& 0 \leq P_{L O A D}^{A}(t) \leq \eta^{A} \cdot P_{L O A D}^{\text {input }}(t) \\
& \text { where } \\
& \qquad \eta^{A}=\text { the efficiency of adjustable load reduction }[\%] \\
& \quad P_{L O A D}^{\text {input }}(t)=\text { the amount of Scheduled adjustable load at } t[\mathrm{kWh}]
\end{aligned}
$$

The shiftable load can be moved in other operation intervals. It is related to the trading prices and generation costs. However, the total amounts of shiftable loads are expressed by equation (17).

$$
\sum_{t=1}^{T} P_{L O A D}^{S}(t)=\sum_{t=1}^{T} P_{L O A D}^{S^{\prime}}(t)
$$

where

$$
P_{L O A D}^{S}(t)=\text { the amount of scheduled shiftable load at } t[\mathrm{kWh}]
$$

Equation (18) shows the optimized shiftable load.

$0 \leq P_{\text {OUT }}(t) \leq P_{L O A D}^{S}(t)$, 
where

$$
P_{\text {OUT }}(t)=\text { the amount of shiftable load at } t[\mathrm{kWh}]
$$

\section{Simulation}

\subsection{Operation condition and input data}

In this paper, electrical power generators are composed of a diesel generator, a CHP, and a $\mathrm{PV}$. The green campus is connected to the power grid. Thermal energy is supplied from a CHP and a HOB without any connection with the thermal utility as mention before. When an adjustable load is more than 1.2 times the reference load, the adjustable load can be reduced with the incentive of $153(\mathrm{kWh})$.

Table 1, Table 2, Table 3, and Figure 2 show input data, where 24 operation intervals are considered $[18,19]$.

Table 1. Input data of energy sources

\begin{tabular}{|c|c|c|c|}
\hline Components & Cost $(\$ / \mathrm{kWh})$ & Minimal capacity $(\mathrm{kWh})$ & Maximal capacity $(\mathrm{kWh})$ \\
\hline DG & 148 & 0 & 200 \\
\hline CHP & 152 & 190 & 480 \\
\hline HOB & 160 & 3 & 100 \\
\hline ESS & 0 & 30 & 100 \\
\hline
\end{tabular}

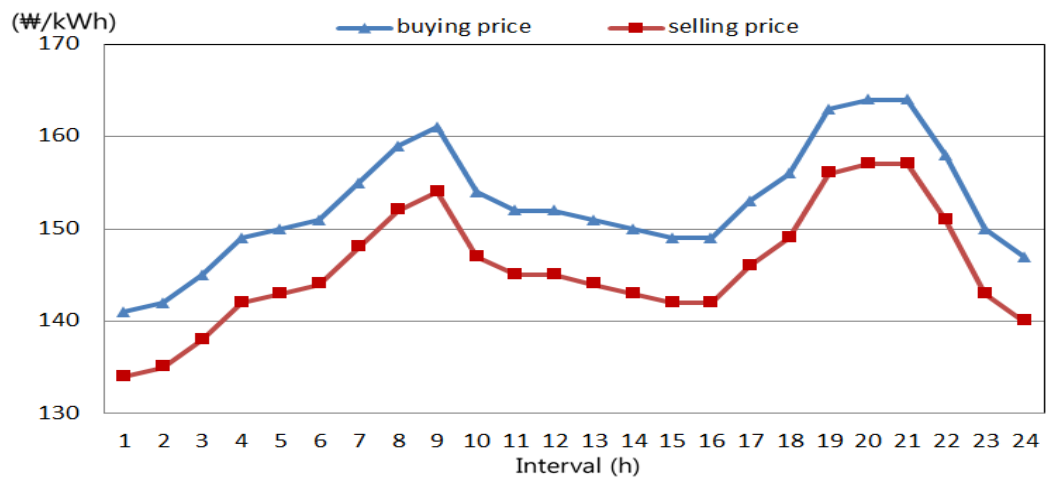

Figure 2. Power trade prices

Table 2. Output of photovoltaic source

\begin{tabular}{|c|c|c|c|c|c|c|c|c|c|c|c|c|}
\hline Interval & 1 & 2 & 3 & 4 & 5 & 6 & 7 & 8 & 9 & 10 & 11 & 12 \\
\hline Output $(\mathrm{kWh})$ & 0 & 0 & 0 & 0 & 5 & 7 & 13 & 15 & 17 & 20 & 22 & 25 \\
\hline Interval & 13 & 14 & 15 & 16 & 17 & 18 & 19 & 20 & 21 & 22 & 23 & 24 \\
\hline Output $(\mathrm{kWh})$ & 23 & 20 & 14 & 10 & 8 & 0 & 0 & 0 & 0 & 0 & 0 & 0 \\
\hline
\end{tabular}


Table 3. Load data

\begin{tabular}{|c|c|c|c|c|c|c|c|c|c|c|c|c|}
\hline Interval & 1 & 2 & 3 & 4 & 5 & 6 & 7 & 8 & 9 & 10 & 11 & 12 \\
\hline Electrical load $(\mathrm{kWh})$ & 418 & 428 & 426 & 425 & 425 & 432 & 434 & 457 & 501 & 526 & 548 & 555 \\
\hline Thermal load $(\mathrm{kWh})$ & 389 & 361 & 370 & 368 & 350 & 369 & 497 & 630 & 567 & 532 & 593 & 561 \\
\hline Interval & 13 & 14 & 15 & 16 & 17 & 18 & 19 & 20 & 21 & 22 & 23 & 24 \\
\hline Electrical load $(\mathrm{kWh})$ & 565 & 576 & 589 & 597 & 587 & 573 & 565 & 545 & 535 & 474 & 448 & 422 \\
\hline Thermal load $(\mathrm{kWh})$ & 584 & 597 & 610 & 563 & 527 & 481 & 490 & 457 & 426 & 440 & 412 & 403 \\
\hline
\end{tabular}

\subsection{Simulation results}

Figure 3 shows the generation outputs as the results of optimal operation by the proposed operation algorithm. Since the operation cost of the diesel generator is lower than that of the CHP, the diesel generator is operated with maximum output to supply power to loads in intervals 4 to 23. Since there is no interconnection with the thermal energy system outside of the green campus, CHP output is dependent on thermal load amounts. Meanwhile, the ESS charges maximally in interval 1 and discharges in intervals 20 and 21 because buying prices are higher than those of other intervals. It means the ESS reduces the operation cost and shows that the energy system of the campus works optimally considering trading prices and generation costs according to design purposes.

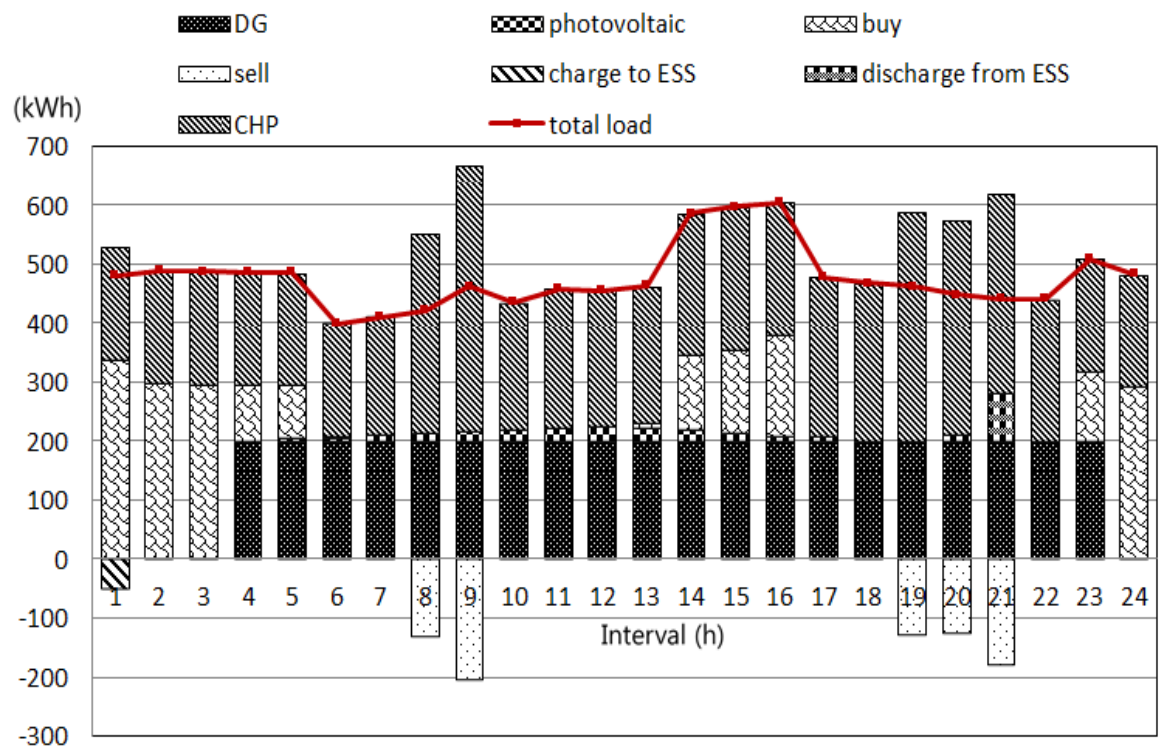

Figure 3. Output of electric energy sources

The CHP produces thermal energy and electric energy together. The thermal energy produced from the CHP can be regarded as having the low price. Relatively, the HOB has higher operation cost than the CHP in terms of thermal energy. Figure 4 shows that the HOB supplies thermal energy during the peak interval of the thermal load. 


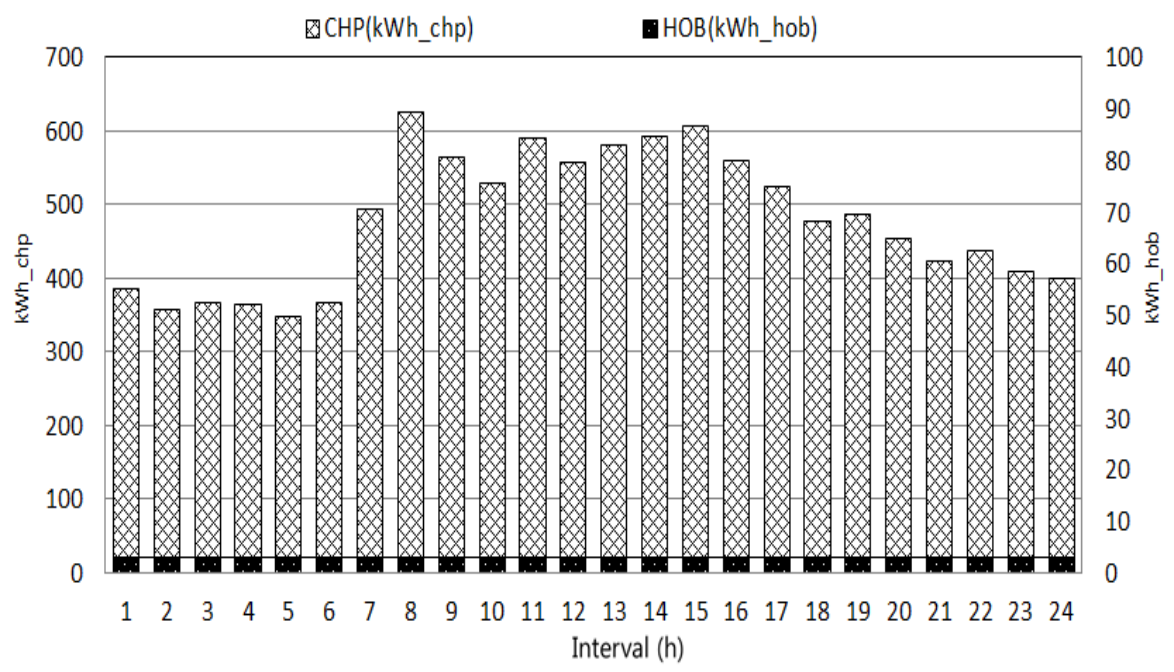

Figure 4. Output of thermal energy sources

\subsection{DR effect}

Figure 5 shows pre-scheduled loads and Figure 6 shows optimal scheduled loads based on DR during each operation interval, respectively. From the result, fixed loads show without any movement but shiftable loads are moved greatly by the proposed optimal algorithm. Especially, shiftable loads in intervals 1-5 and 14-16 are moved more greatly than those of other intervals because these intervals have relatively lower trading prices. In the case of adjustable loads, there is no action for adjustable loads in intervals 9 and 22 because adjustable conditions are not satisfied. Thus, adjustable loads are maintained in intervals 9 and 22. On the other hand, other adjustable loads get the maximum incentive by reducing loads.

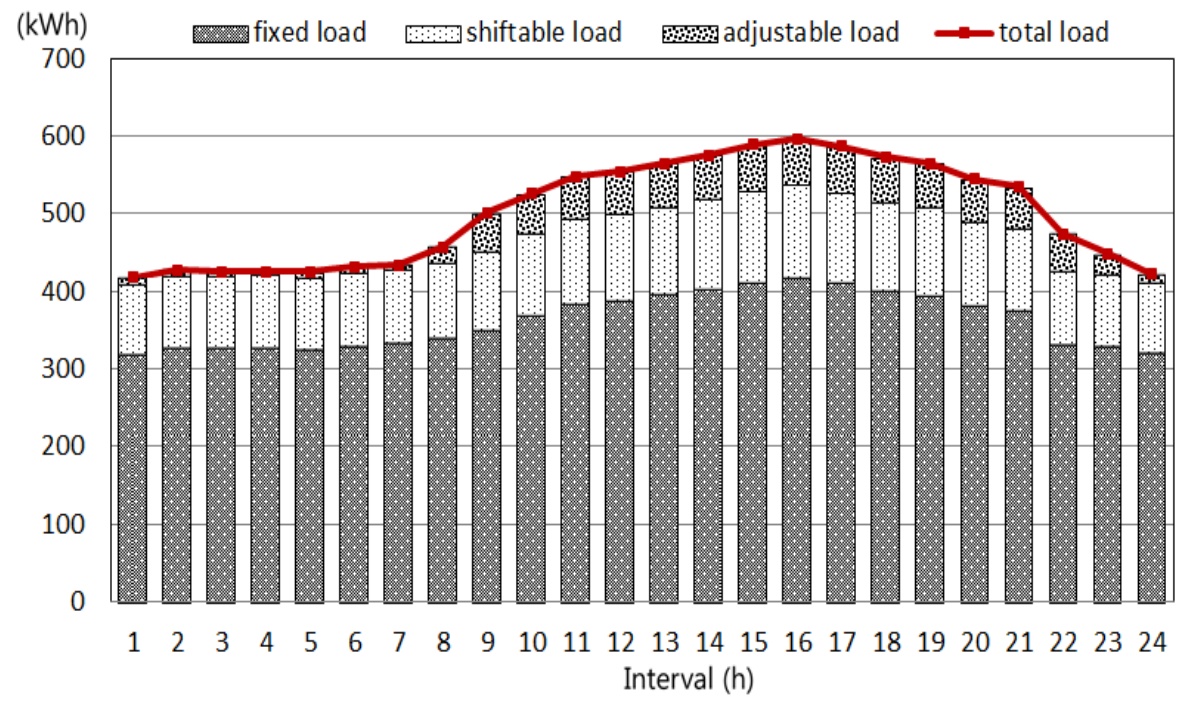

Figure 5. Pre-scheduled loads 


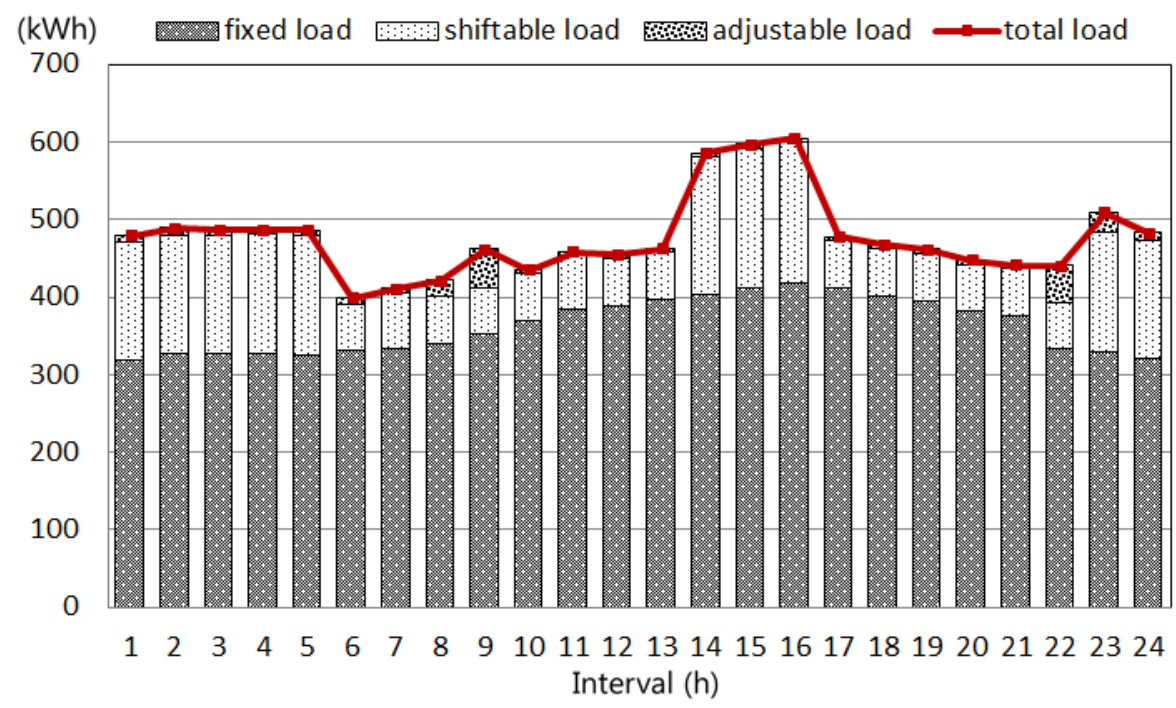

Figure 6. Optimal scheduled loads based on DR

\section{Conclusion}

In this paper, a mathematical model of optimal operation for the energy system of the green campus has been proposed. The mathematical model has been based on DR. For this, loads have been composed of three types: the fixed load, shiftable load, and adjustable load based on incentive. To show the feasibility of the proposed model, the simulation has been performed.

As a future work, an interconnection with thermal utility grid will be added to optimal operation of the energy system of the green campus.

\section{Acknowledgement}

This work was supported by the Green Campus Research Grant of Incheon National University in 2013.

\section{References}

[1] S. J. Choi, S. J. Park, D. J. Kang, S. J. Han, and H. M. Kim, "A Microgrid Energy Management System for Inducing Optimal Demand Response", Proceedings of IEEE International Conference on Smart Grid Communications, (2011) October 17-20, pp. 19-24; Brussels, Belgium.

[2] B. Zhao, Y. Shi, X. Dong, W. Luan, and J. Bornemann, "Short-Term Operation Scheduling in RenewablePowered Microgrids: A Duality-Based Approach", IEEE Transactions on Sustainable Energy, vol. 5, no. 1, (2013), pp. 209-217.

[3] J. H. Lee and H. M. Kim, "LP-based Mathematical Model for Optimal Microgrid Operation Considering Heat Trade with District Heat System”, IJEIC, vol. 4, no. 4, (2013), pp. 13-21.

[4] J. H. Lee, H. M. Kim, Y. H. Im, and J. Y. Lee, "An Optimal Operation Model for Centralized Micro-Energy Network Considering Electric Heating”, IJEIC, vol. 5, no. 5, (2014), pp. 55-64.

[5] K. H. Kim, "Optimal Operation Scheme and Reliability Index Improvement of Micro Grid using Energy Storage Systems”, KIEE Transactions, vol. 63, no. 2, (2014), pp. 205-210.

[6] H. M. Kim, Y. J. Lim, and T. Kinoshita, "An Intelligent Multiagent System for Autonomous Microgrid Operation”, Energies, vol. 5, no. 9, (2012), pp. 3347-3362.

[7] Green Growth Korea Report, A Study on the Long-Term Development of Green Campus, (2013).

[8] Ministry of Environment Report, A Comparative Study of Green Campus Cases and Programs between Korea and Other Countries, (2011). 
[9] Korean Association for Green Campus Initiative Report, Examples of Green Campus, (2009).

[10] Gyeonggi Research Institute Report, Development of Green Campus Practice Manual and Campus GHG Inventory Model, (2010).

[11] V. Jayadev and K. S. Swarup, "Optimization of Microgrid with Demand Side Management using Genetic Algorithm", Proceedings of IET Conference on Power in Unity: A Whole System Approach, (2013) October 16-17, pp. 1-6; London, United Kingdom.

[12] The EU's 7th Framework Programme Report, Shift, Not Drift: Towards Active Demand Response and Beyond, (2013).

[13] J. R. Won and J. H. Kim, "A Study on Setting Base Line Load of Price-based Load Management", Proceedings of Conference on Power Engineering Society of KIEE, (2008) November 7-8, pp. 357-359; Jeju, Republic of Korea.

[14] P. Faria, J. Soares, Z. Vale, H. Morais, and T. Sousa, "Modified Particle Swarm Optimization Applied to Integrated Demand Response and DG Resources Scheduling", IEEE Transactions on Smart Grid, vol. 4, no. 1, (2013), pp. 606-616.

[15] C. Vivekananthan, Y. Mishra, G. Ledwich, and F. Li, "Demand Response for Residential Appliances via Customer Reward Scheme", IEEE Transactions on Smart Grid, vol. 5, no. 2, (2014), pp. 809-820.

[16] C. O. Adika, and L. Wang, "Demand-Side Bidding Strategy for Residential Energy Management in a Smart Grid Environment", IEEE Transactions on Smart Grid, vol. 5, no. 4, (2014), pp. 1724-1733.

[17] Z. Tan, P. Yang, and A. Nehorai, "An Optimal and Distributed Demand Response Strategy with Electric Vehicles in the Smart Grrid”, IEEE Transactions on Smart Grid, vol. 5, no. 2, (2014), pp. 861-869.

[18] "POWER Business and Technology for the Global Generation Industry", http://www.powermag.com.

[19] Korea Electrotechnology Research Institute Report, Development of Real-Time Operating System Power Demand Resources (Final Report), (2012). 